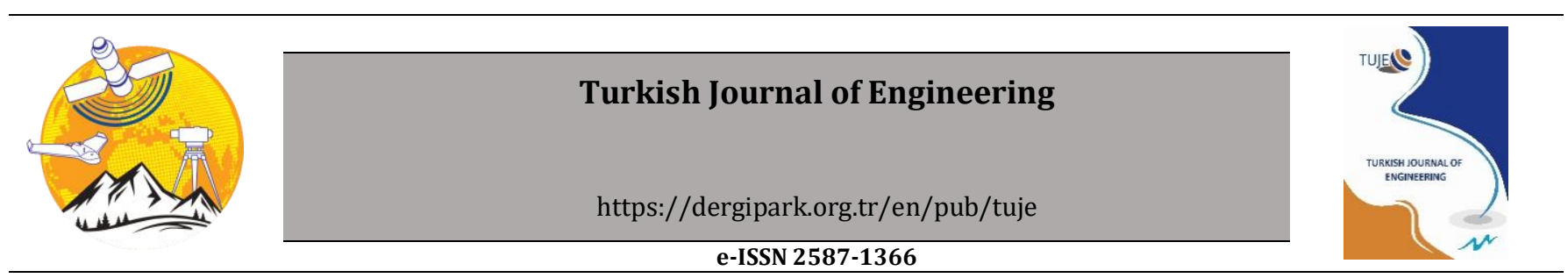

\title{
An application to error and uncertainty analysis in industrial type dryer experiments
}

\author{
Ahmet Erhan AKAN ${ }^{* 1}$, Fatih ÜNAL ${ }^{2}$ (D) \\ ${ }_{1}^{1}$ Tekirdag Namık Kemal University, Department of Machinery and Metal Technology, Tekirdağ, Turkey \\ 2Mardin Artuklu University, Department of Machinery and Metal Technology, Mardin, Turkey
}

\author{
Keywords \\ Convection dryer \\ Error analysis \\ Uncertainty analysis \\ Drying test \\ Stenter
}

\begin{abstract}
In this study, information is given about the driers commonly used in the industry and the experimental errors and uncertainties that will be encountered in the experiments using these driers are tried to be explained by using the data obtained from the experiments carried out in an 8 chambers hot oil heated stenter, which is a conveyor type convection dryer. The fabric used in the experiments is the Thessaloniki type fabric, containing $67 \%$ cotton and $37 \%$ polyester. The experiments were carried out at a drying air temperature of $160 \stackrel{\circ}{\circ} \mathrm{C}$ and a fabric advance rate of $23 \mathrm{~m} / \mathrm{h}(0.383 \mathrm{~m} / \mathrm{s})$. Thus, the example of error analysis in such experimental studies is provided and criteria that may cause an error for drying systems are discussed. As a result of the uncertainty analysis, the largest uncertainty in the system occurred in temperature measurements at $\pm 0.367- \pm 0.568 \stackrel{\circ}{\circ} \mathrm{C}$ values and the error rate for the whole system was found to be $4.08 \%$. In terms of conducting the experiments in real production conditions and the materials and methods used in the experiments, this study is thought to will be help researchers that working on drying systems in their experimental studies.
\end{abstract}

\section{INTRODUCTION}

Although drying is considered to be the removal of water or other liquids from gases, liquids or solids; the most common use is defined as the process of removing water or other volatile substances from solids utilizing thermal methods (Güngör and Özbalta 1997). Factors such as material type, structure, ambient conditions, air quality, and speed of drying air are effective in drying processes (Akarslan 2002). Drying is a complex process involving simultaneous heat, mass, and momentum transfer (Haghi and Amanifard 2008). It is perhaps the oldest and most common method used by mankind to protect their food (Doymaz 2004). Drying is known to facilitate the usage of the product, provide microbial protection and prolong the shelf life of the product (Koyuncu et al. 2007). However, the drying process is not limited to the food industry (Akan et al. 2015). It is an important process in the industrialized world in the chemical, agricultural, biotechnology, polymer, ceramic, perfumery, paper, mining, and wood industries. The use of hot air in the drying process, which is the most common, has caused these processes to be the most energy-consuming in the industry due to the high evaporation temperature and the inefficiency of the hot air used. While the drying process consumes a lot of energy, large amounts of $\mathrm{CO}_{2}$ are released into the environment (Mujumdar 2006). In many industrial enterprises, the energy consumed for drying has an important share in the total energy consumption of the establishment. This rate can reach $6 \%$ in chemistry, $5 \%$ in textile, $11 \%$ in ceramic and other construction materials production, $11 \%$ in timber drying, $12 \%$ in food and agricultural products, and 33\% in the paper industry (Güngör 2013). This makes it necessary to use drying systems as efficiently as possible. Therefore, it is inevitable that the drying systems are chosen for their purpose. Table 1 shows the energy consumed by the different types of dryers per unit of water removed from the material to be dried.

For the material to be dried, the following points should be considered in the selection of the drying method (Doğanay 2009);

a- Drying behavior of the material to be dried: Amount of moisture before drying, type of moisture (bound water or unbound water), moisture content after drying, drying temperature, and drying time.

b- Properties of dry matter to be obtained: Particle size, concentration, moisture content, brittleness, etc. properties. 
c- Processes related to drying operation: Continuous or batch drying preference, pre- or post-drying process requirement, drying time, drying temperature, position and movement in the dryer, and the capacity of the dryer.

d- Operating conditions of the dryer: The environment of the dryer, the dimensions of the dryer, thermodynamic properties and cleaning of the drying air, and vibration and noise of the dryer.

Accordingly, the drying methods used in the industry are presented in Table 2 (Doğanay 2009).

Table 1. Energy consumed per water removed from the product by dryer types (Güngör 2013; Basaran et al. 2004).

\begin{tabular}{ll}
\hline Dryer Type & $\begin{array}{l}\text { Evaporating } \\
\text { water } \\
(\mathrm{MJ} / \mathrm{kg})\end{array}$ \\
\hline $\begin{array}{l}\text { Heat pump dryer } \\
\text { Direct exhaust gas dryer }\end{array}$ & $0.5-0.8$ \\
Air-operated dryer between & $3.2-3.8$ \\
$70-100$-C & $4.5-5.5$ \\
$\begin{array}{l}\text { Desiccant operating with exhaust gases } \\
\text { from the boiler }\left(4000^{\circ} \mathrm{C}\right)\end{array}$ & $5.0-6.0$ \\
$\begin{array}{l}\text { Desiccant operating with exhaust gases } \\
\text { from the boiler }\left(2000^{\circ} \mathrm{C}\right)\end{array}$ & $9.0-12.0$ \\
Reverse flow, with Tray - Belt & $8.0-16.0$ \\
Reverse flow, with Shelf - Tunnel & $6.0-16.0$ \\
Cross-flow, with Tray-Band & $5.0-12.0$ \\
Vacuum, with Tray - Belt - Plate & $3.5-8.0$ \\
\hline
\end{tabular}

Table 2. Drying methods

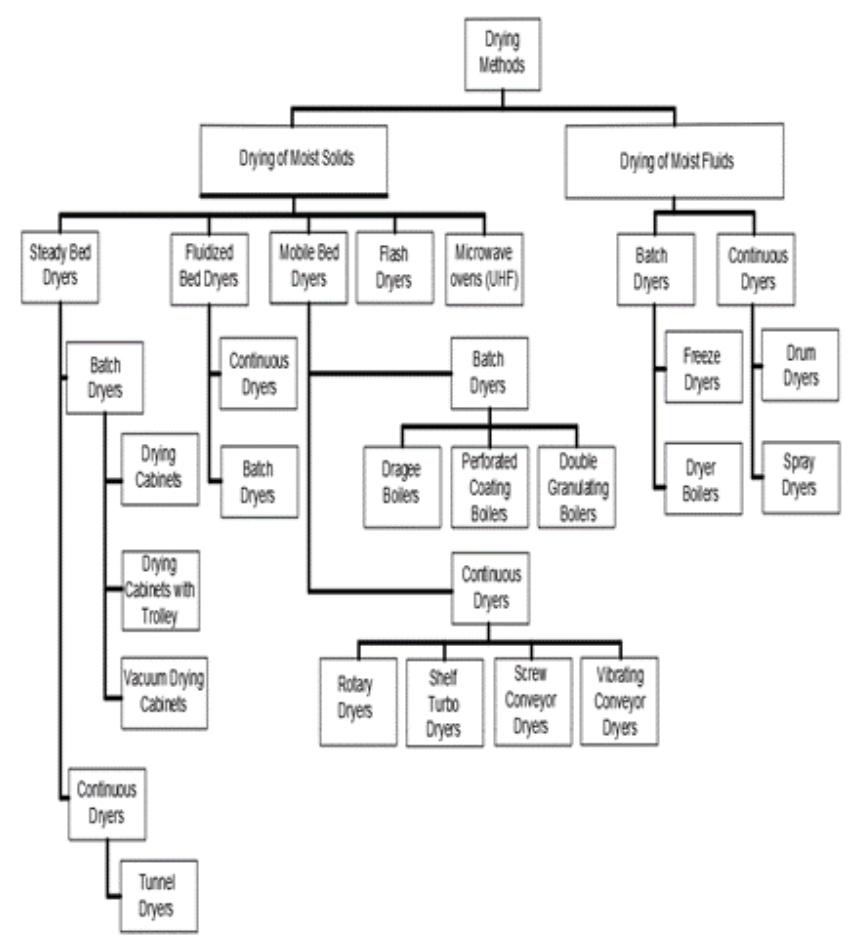

Experimental studies on the above-mentioned drying systems have always given researchers more precise and more accurate information than theoretical studies (Akpınar 2006). However, the information obtained from the experimental studies also depends on the conducting of the experiment, the selection of measuring instruments, the calibration, and the reading of the obtained values. In general, such parameters that affect the accuracy of experimental data are called experimental errors. Another factor is the accuracy of the measuring instruments, which is called uncertainty. In general, two kinds of errors are encountered in the data obtained from the experiments. The first is the test set and measuring devices, and the second is the error caused by the person or persons experimenting. The first of these errors can be lowered by correctly calibrated test equipment with high sensitivity values and test devices established by standards, the latter can be reduced to the extent possible by the experience of the person performing the experiments, but completely accurate results still cannot be achieved. These error amplitudes are generally not known and are called errors in the literature (Akpınar 2006; Midilli 2001; Akpınar 2002). It is also possible to divide the faults originating from the so-called first type of errors, which are the test set and measuring devices into three main groups (Holman 1971). The first is the errors caused by the manufacture of machinery, equipment, and devices used in the tests, the second is the fixed errors that occur during the re-reading of the same magnitude of unknown reason, and the third is the random errors caused by random electronic oscillations, friction, heat loss, etc. It is difficult to distinguish between many fixed errors and random errors (Akpınar 2006; Holman 1971). However, since the fixed errors are always read at the same values during the experiment, these errors can be corrected by using correctly calibrated test equipment.

Numerous experimental studies are possible in the literature. However, it is seen that it does not have an error analysis, which shows how accurate the experiment is in most of them. This study aims to present an example of error analysis in drying systems, especially for researchers working on drying systems.

\section{MATERIALS and METHOD}

The experimental data obtained in this study were obtained from an 8-chamber hot oil heating ram machine used in a textile factory in Corlu/Tekirdağ (Akan et al. 2015). The schematic representation of the ram machine is presented in Figure 1. The fabric used in the experiments is the Thessaloniki type fabric, containing $67 \%$ cotton and $37 \%$ polyester. The dry weight of the fabric was kept at $20{ }^{\circ} \mathrm{C}$ in $65 \%$ relative humidity (standard weather conditions) for 24 hours in the

ELECTRO-MAG M3025P oven and the arithmetic average was determined as $320 \mathrm{gr} / \mathrm{m}^{2}$, after which 5 samples taken from the fabric with DVT D100 circular sample cutter were measured with DESIS THB 600 precision scales. Before starting the tests, the fabric thickness was determined as $1.2 \mathrm{~mm}$ with the help of the TESTEX TF121 fabric thickness measuring device. Also, before the drying operation, the relative humidity of the fabric was determined as $80 \%$ with HYGRO FASTER EKV fabric moisture measuring device and the wet fabric weight was determined as $576 \mathrm{~g} / \mathrm{m}^{2}$ with the help of precision scales. The fabrics to be dried in the ram machine were washed in the foulard part before they enter the drying cabinets and were purified from unwanted foreign materials and subjected to the predrying process by crushing them between the rollers in the same part (Figure 1). After pre-drying, fabric surface 
temperature was measured as $30^{\circ} \mathrm{C}$ by using DIGITRON THERMAPRO 2 data logger with K Type Probe.

The experiments were carried out at a drying air temperature of $160{ }^{\circ} \mathrm{C}$ and a fabric advance rate of 23 $\mathrm{m} / \mathrm{d}(0.383 \mathrm{~m} / \mathrm{s})$. The nozzles in each cabinet were selected from 3 nozzle units and the drying air velocity was measured as $35 \mathrm{~m} / \mathrm{s}$ with the help of TESTO 350 $\mathrm{M} / \mathrm{XL}$ portable gas analyzer. During the drying operation, the fabric surface temperatures were determined by DIGITRON THERMOPRO 2 data logger at the inlet and outlet points of each cabin, and the relative humidity and temperature values of the humid air around the boundary layer on the fabric were determined by DELTA OHM HD2301 humidity and temperature measuring device. Figure 2 shows the schematic representation of the measurement locations on the ram machine.

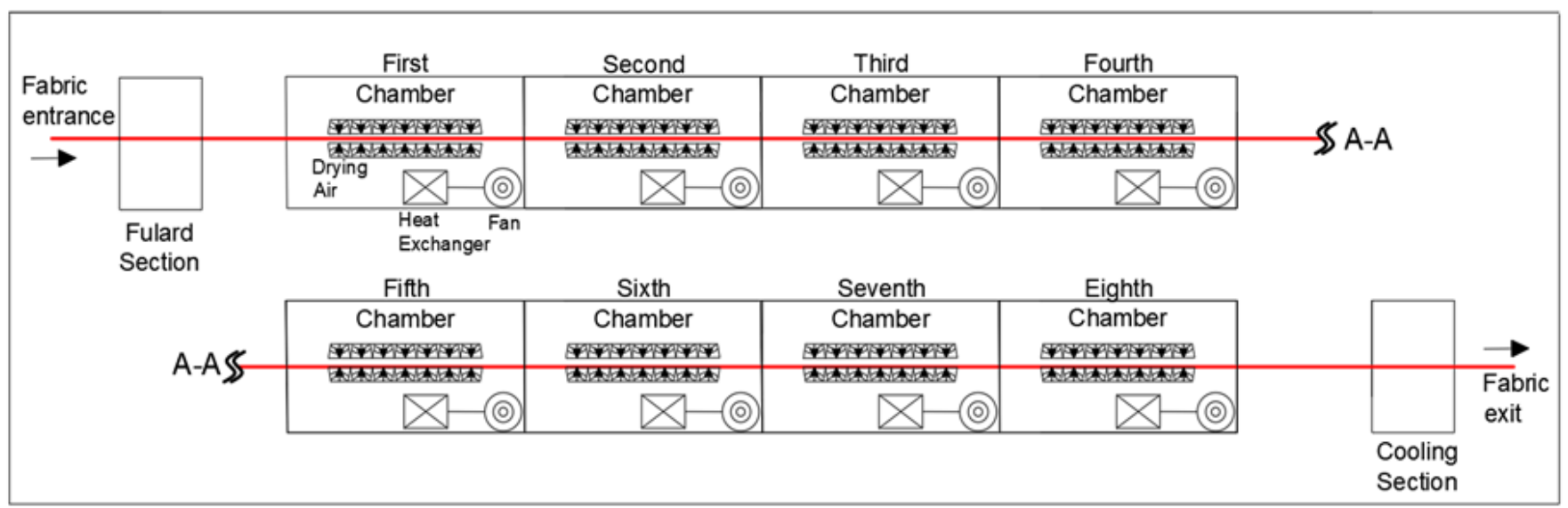

Figure 1. Schematic representation of the ram machine

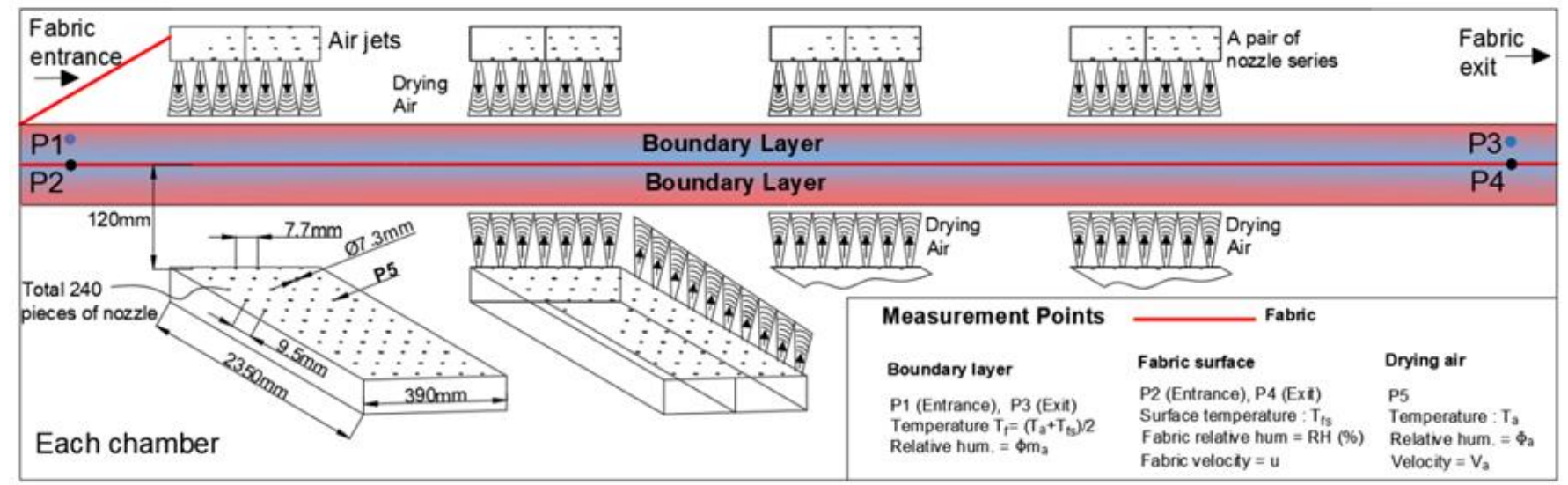

Figure 2. Schematic representation of measuring points on the ram machine (Akan and Ozkan 2019)

The measurement devices used during the experiments and their sensitivity are given in Table 3 and the values of the experimental data obtained are given in Table 4.

Table 3. Brands and accuracy values of measuring devices

\begin{tabular}{ll}
\hline Measurement Devices Brands and Models & Sensitivity \\
\hline $\begin{array}{l}\text { TESTO 350M/XL, Portable gas analyser } \\
\text { (Air velocity measurement) }\end{array}$ & $5 \%(\mathrm{~m} / \mathrm{s})$ \\
HYGRO FASTER EKV & $0.8 \%(\mathrm{RH})$ \\
(Fabric moisture measurement) & \\
$\begin{array}{l}\text { DELTA OHM HD 2301 } \\
\text { (Moist air, humidity - temperature) }\end{array}$ & $0.1 \%\left(\mathrm{RH},{ }^{\circ} \mathrm{C}\right)$ \\
HP475AC1R Model Probe & \pm 1.5 \\
(Moist air, humidity - temperature) & $3 \%[\mathrm{RH}]$ \\
$\begin{array}{l}\text { DIGITRON THERMAPRO 2 } \\
\text { (K type probe, Fabric surface temp.) }\end{array}$ & $0.5 \%\left({ }^{\circ} \mathrm{C}\right)$ \\
DESIS THB 600 Precision scales & $0.01[\mathrm{~g}]$ \\
$\begin{array}{l}\text { ELEKTRO-MAG M3025P } \\
\text { (Drying-oven) }\end{array}$ & $\pm 1{ }^{\circ} \mathrm{C}$ \\
$\begin{array}{l}\text { TESTEX TF121 } \\
\text { (Fabric thickness measurement) } \\
\text { DVT 100 (Circular sample cutter) }\end{array}$ & $0.01 \mathrm{~mm}$ \\
\hline
\end{tabular}

\section{ERROR AND UNCERTAINTY ANALYSIS}

Assumptions made when determining experimental error analysis are given below:

* The test set-up was a dryer operating under actual production conditions established by the standards.

* The measuring devices were correctly calibrated.

* It was assumed that there were no errors in the production of measuring devices.

* The determined error values include both fixed errors and random errors.

According to this; the expression that gives the total error that may occur due to fixed errors, random errors and manufacturing errors that may occur in the measurement of the experiments can be written as in Equation 1 according to Kline and McClintock (Akpınar 2006; Holman 1971).

$$
\mathrm{W}_{\mathrm{R}}=\left[\left(\frac{\partial \mathrm{R}}{\partial_{\mathrm{x} 1}} \mathrm{w}_{1}\right)^{2}+\left(\frac{\partial \mathrm{R}}{\partial_{\mathrm{x} 2}} \mathrm{w}_{2}\right)^{2}+\cdots\left(\frac{\partial \mathrm{R}}{\partial_{\mathrm{xn}}} \mathrm{w}_{\mathrm{n}}\right)^{2}\right]^{\frac{1}{2}}
$$




$$
\frac{W_{R}}{R}=\left[\left(\frac{W_{x 1}}{x_{1}}\right)^{2}+\left(\frac{W_{x 2}}{x_{2}}\right)^{2}+\cdots\left(\frac{W_{x n}}{x_{n}}\right)^{2}\right]^{1 / 2}
$$

Here, $\mathrm{R}, \mathrm{x} 1, \mathrm{x} 2 \ldots \mathrm{x}$ is a given function of the independent variables, $\mathrm{w}_{1}, \mathrm{w}_{2}, \ldots, \mathrm{w}_{\mathrm{n}}$ is the uncertainty of the independent variables. The errors that can be made in the drying tests, considering the independent variables that may create the above-mentioned error, are given in Table 5 and the values of these errors are given in Table 6.

The elements that may cause error shown in Table 5 were calculated with the help of Equation 1 and Table 6 was obtained.
As can be seen from Table 6, the biggest uncertainties in the system can be detected immediately by using uncertainty analysis. This shows the superiority of uncertainty analysis. The greatest uncertainty in the system occurred at $\pm 0.367- \pm 0.568{ }^{\circ} \mathrm{C}$ in temperature measurements. It can then be seen that the determination of the mass of water evaporated from the fabric occurs with an uncertainty value of $\pm 0.250 \mathrm{~g}$. If the error value of the entire system is to be investigated, this result can be reached by using the values given in Table 7 and one of the equations given above.

Table 4. Experimental data

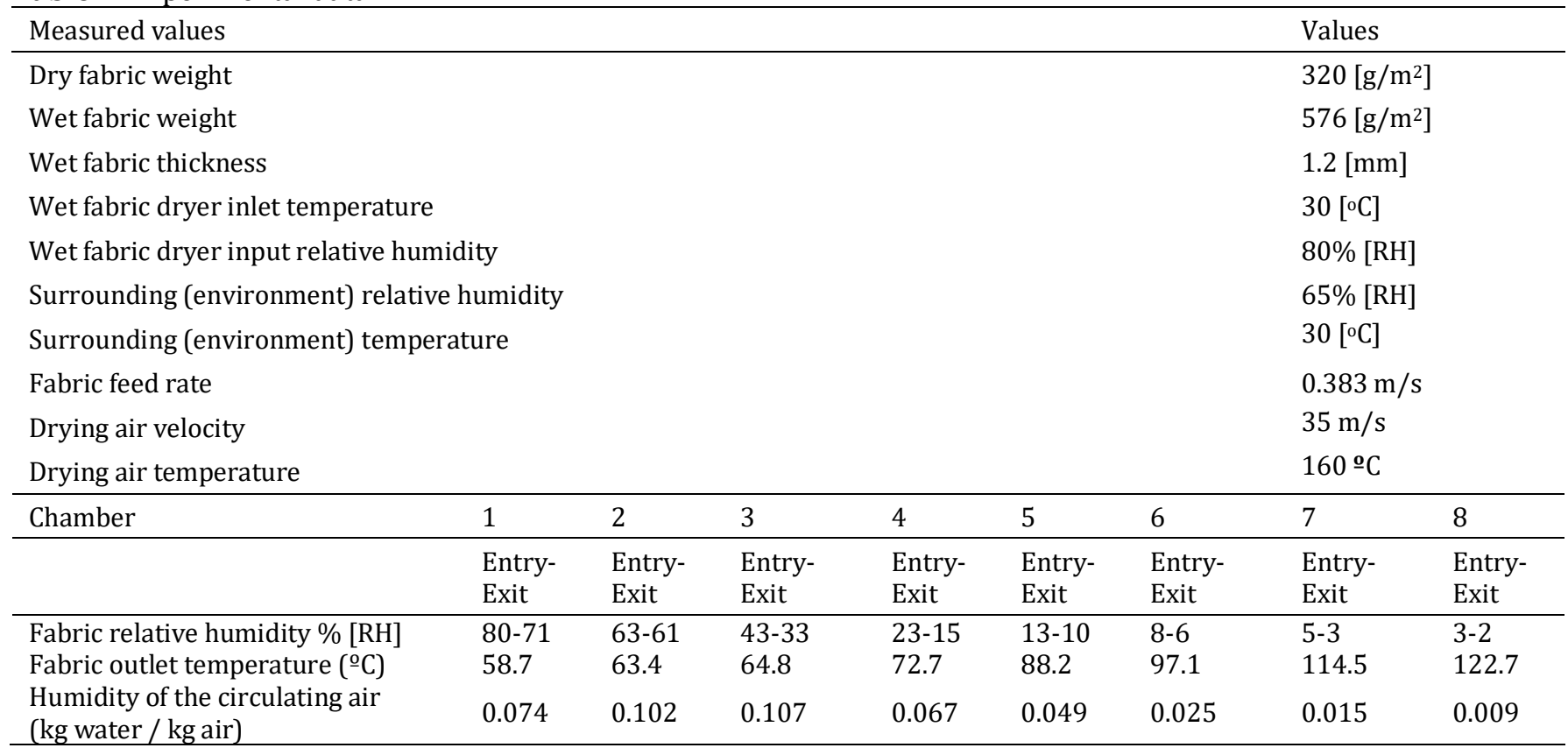

Table 5. Possible errors that can be made in drying experiments

\begin{tabular}{|c|c|c|c|}
\hline Error constituents parameters & Error & Symbol & Unit \\
\hline Error caused by the fabric thickness measurement & \pm 0.01 & $\mathrm{~W}_{\mathrm{ft}}$ & $\mathrm{mm}$ \\
\hline Error caused by the circular sample cutter measurement & \pm 0.04 & $W_{\text {fct }}$ & $\mathrm{cm}^{2}$ \\
\hline Error caused by thermocouples & $\pm 0.25-0.50$ & $W_{\text {ther }}$ & $\stackrel{\mathrm{o}}{\mathrm{C}}$ \\
\hline Error caused by connection elements and locations & \pm 0.1 & $\mathrm{~W}_{\text {cel }}$ & ${ }^{\mathrm{o}} \mathrm{C}$ \\
\hline Error that can be made in temperature measurement at dryer entry-exit points & \pm 0.25 & $\mathrm{~W}_{\mathrm{tm}}$ & ${ }^{\circ} \mathrm{C}$ \\
\hline Error that can be made to measure drying air nozzle output temperature & \pm 0.01 & $W_{\text {not }}$ & $\stackrel{\circ}{ } \mathrm{C}$ \\
\hline Error in measuring moist air (exhaust) temperature & \pm 0.01 & $\mathrm{~W}_{\text {mat }}$ & ${ }^{\circ} \mathrm{C}$ \\
\hline Error in measuring ambient air temperature & \pm 0.01 & $\mathrm{~W}_{\text {ait }}$ & $\stackrel{\circ}{\circ}$ \\
\hline Error in measuring fabric surface temperature & \pm 0.005 & $\mathrm{~W}_{\mathrm{fst}}$ & ${ }^{\circ} \mathrm{C}$ \\
\hline Error caused by the time meter & \pm 0.1 & $\mathrm{~W}_{\mathrm{Tm}}$ & s \\
\hline Reader-induced error & \pm 0.1 & $\mathrm{~W}_{\text {trie }}$ & s \\
\hline Error caused by precision scale & \pm 0.01 & $\mathrm{~W}_{\mathrm{pc}}$ & g \\
\hline Reader-induced error & \pm 0.01 & $\mathrm{~W}_{\text {mrie }}$ & $\mathrm{g}$ \\
\hline Error caused by fabric & \pm 0.25 & $\mathrm{~W}_{\mathrm{f}}$ & g \\
\hline Error caused by anemometer sensitivity & \pm 0.05 & $\mathrm{~W}_{\mathrm{as}}$ & $\mathrm{m} / \mathrm{s}$ \\
\hline Error caused by drying airflow leaks & \pm 0.1 & $\mathrm{~W}_{\mathrm{fl}}$ & $\mathrm{m} / \mathrm{s}$ \\
\hline Error caused by fabric speed settings & \pm 0.015 & $\mathrm{~W}_{\mathrm{fss}}$ & $\mathrm{m} / \mathrm{s}$ \\
\hline Error caused by the sensitivity of thermohygrometer & $\pm 0.015-0.03$ & $\mathrm{~W}_{\text {hmst }}$ & $\mathrm{RH}$ \\
\hline Error caused by the placement of the thermohygrometer around the boundary layer & \pm 0.1 & $\mathrm{~W}_{\mathrm{hbl}}$ & $\mathrm{RH}$ \\
\hline Reader-induced error & \pm 0.1 & Whrie & $\mathrm{RH}$ \\
\hline Error caused by the sensitivity of the moisture analyser & \pm 0.008 & $\mathrm{~W}_{\text {sma }}$ & g \\
\hline Reader-induced error & \pm 0.001 & $\mathrm{~W}_{\text {fmcrie }}$ & g \\
\hline Error from reading table values of physical properties & $\pm 0.1-0.2$ & $\mathrm{~W}_{\mathrm{vpp}}$ & $\%$ \\
\hline
\end{tabular}


Table 6. Errors that may occur in experiments

\begin{tabular}{lll}
\hline Error constituents parameters & Total error & Unit \\
\hline Possible errors in fabric thickness measurement & \pm 0.01 & $\mathrm{~mm}$ \\
Possible errors in circular sample cutter measurement & \pm 0.04 & $\mathrm{~m}^{2}$ \\
Possible errors in temperature measurement & $\pm 0.367- \pm 0.568$ & ${ }^{\circ} \mathrm{C}$ \\
Possible errors in the time measurement & \pm 0.141 & $\mathrm{~s}$ \\
Possible errors in the measurement of mass losses & \pm 0.250 & $\mathrm{~g}$ \\
Possible errors caused by velocity measurement & \pm 0.112 & $\mathrm{~m} / \mathrm{s}$ \\
Possible errors in the relative humidity measurement & $\pm 0.142- \pm 0.147$ \\
Possible errors that may occur in determination of fabric moisture content & $\pm 0.008 \mathrm{RH}$ \\
Other errors & $\pm 0.1-0.2$ & $\mathrm{~g}$ \\
\hline
\end{tabular}

Table 7. Parameters and sensitivities of measurement

\begin{tabular}{|c|c|c|c|c|c|}
\hline Parameter & & Unit & Sensitivities & $\begin{array}{l}\text { Measured min.-max. } \\
\text { values }\end{array}$ & $\begin{array}{c}\text { Measured average } \\
\text { values }\end{array}$ \\
\hline \multirow{2}{*}{ Velocity } & Air & \multirow{2}{*}[\mathrm{m}/\mathrm{s}]{} & 0.05 & $21.85-48.15$ & 35 \\
\hline & Fabric & & 0.015 & 0.383 & 0.383 \\
\hline \multirow{4}{*}{ Temperature } & Fabric & \multirow{4}{*}[\underline{\mathbf{o}}\mathrm{C}]{} & 0.005 & $27-152$ & 89.5 \\
\hline & Drying air & & 0.01 & $152-168$ & 160 \\
\hline & Moist air & & 0.01 & 52-102 & 77 \\
\hline & Environment & & 0.01 & $26.3-33.78$ & 30 \\
\hline \multirow{2}{*}{ Relative Humidity } & Moist air & \multirow{2}{*}{$\% \mathrm{RH}$} & $0.015-0.03$ & $59-61$ & 60 \\
\hline & Environment & & $0.015-0.03$ & $5.1-72$ & 60 \\
\hline Moisture Content & Fabric & $\% \mathrm{RH}$ & 0.008 & $3.27-63$ & 31.6 \\
\hline Weight & Fabric & {$[\mathrm{g}]$} & 0.01 & $300-550$ & 425 \\
\hline Time & Fabric & {$[\mathrm{s}]$} & 0.5 & $60-66.98$ & 62.66 \\
\hline Thickness & Fabric & {$[\mathrm{mm}]$} & 0.01 & $1.0-1.4$ & 1.2 \\
\hline Square Measure & Fabric & {$\left[\mathrm{cm}^{2}\right]$} & 0.04 & 98-102 & 100 \\
\hline
\end{tabular}

The error analysis of the whole system was found to be $4.08 \%$. This value is among the acceptable values in the literature.

\section{CONCLUSION}

In this study, experimental error and uncertainty analysis of drying systems that are running on to give an example in order to researchers, 8 chambers hot oil heated convection type dryer machine which is a ram machine using the data obtained from the experiments, error and uncertainty analysis was conducted. In general, error elements that can be encountered in drying systems experiments have been discussed. As a result of uncertainty analysis, the largest uncertainty in the system occurred in temperature measurements with \pm $0.367- \pm 0.568{ }^{\circ} \mathrm{C}$ values and error rate for the whole system was $4.08 \%$. When determining the error rate, it was assumed that vulgar errors caused by personal errors or unexpected events such as making an arithmetic processing error or writing (-) instead of $(+)$ did not occur. At the same time, the values of method errors, device and measurement device errors in the systematic error group were evaluated by taking into account the sensitivity values of the measurement devices used. It is inevitable that the total error rate will be reduced further by selecting those with more appropriate sensitivity values for the measurement devices used. On the other hand, the constant change of test conditions due to the conduct of experiments under actual production conditions has been seen to result in a large increase in the values of random errors caused by unknown, uncontrollable errors. As a result, it was concluded that experimental data closer to the actual values would be obtained when experimental conditions were kept under control and sensitivity values specific to the experiments were used by high-sensitivity devices.

\section{REFERENCES}

Akan A E \& Özkan D B (2019). Experimental examination and theoretical modelling of drying behaviour in the ram machine. Drying Technology, DOI: 10.1080/07373937.2019.1662436.

Akan A E, Özkan D B \& Ünal F (2015). Energy and exergy analysis of hot oil heated convection dryer. ULIBTK'15 20. National Thermal Science and Technique Congress, Balıkesir, Turkey.

Akarslan, F. (2002). Effect of textile material properties on drying performance. Msc. Thesis, University of Süleyman Demirel, Isparta, Turkey (in Turkish).

Akpınar E K (2002). Development of a cyclone type dryer for agricultural products. PhD Thesis, University of Firat, Elazı̆g, Turkey. (in Turkish).

Akpinar E K (2006). An example of error analysis in experimental studies: error analysis in drying experiments. Engineer and Machine, 46(540), 4150. (in Turkish).

Basaran B, Bitlisli B O, Sari Ö, Özbalta N \& Güngör A (2004). New technologies in leather drying: Heat Pump Dryers. I. National Leather Symposium, University of Ege, İzmir, Turkey, 633-648.

Doğanay T (2009). Drying. Modern Pharmaceutical Technology, TEB Pharmacy Academy Publications, Ankara, Turkey, 17-47 (in Turkish).

Doymaz I (2004). Drying kinetics of white mulberry. Journal of Food Engineering, 61(3), 341-346. DOI: 10.1016/S0260-8774(03)00138-9

Güngör A \& Özbalta N (1997) Industrial drying systems. III. National Installation Engineering Congress 
Proceedings Book, İzmir, Turkey, 737-747 (in Turkish).

Güngör A (2013). Dryers and Drying Technologies Used in Vegetable and Fruit Drying. 11th National Installation Engineering Congress, İzmir, Turkey, 43-63 (in Turkish).

Haghi A K \& Amanifard N (2008). Analysis of heat and mass transfer during microwave drying of food products. Brazilian Journal of Chemical Engineering, 25(3), 491-501. ISSN 1678-4383

Holman J P (1971). Experimental Methods for Engineers. McGraw-Hill, New York, USA.
Koyuncu T, Pinar Y \& Lule F (2007). Convective drying characteristics of azarolered (Crataegus monogyna Jacq.) and yellow (Crataegus aronia Bosc.) fruits. Journal of Food Engineering, 78(4), 1471-1475. DOI: 10.1016/j.jfoodeng.2005.09.036

Midilli A (2001). Distillation of Wastewater by Natural Vacuum Technique. PhD Thesis, University of Karadeniz Technical, Trabzon, Turkey (in Turkish).

Mujumdar A S (2006). Hand book of industrial drying. CRC Press, Lodz, Poland.

(c) Author(s) 2021.

This work is distributed under https://creativecommons.org/licenses/by-sa/4.0/ 